\title{
HIINA KEELE SUGULUSEST UGRI KEELTE JA ERITI SOOME-EESTI KEELEGA (1895)
}

\author{
Karl August Hermann \\ Tõlkinud ${ }^{l}$ Urmas Sutrop
}

Kokkuvõte. Eesti 19. sajandi väljapaistev keeleteadlane, entsüklopedist ja helilooja Karl August Hermann (1851-1909) toob välja tunnused, mis võiksid osutada ugri, st soome-ugri ning altai keelte, sh eesti ja soome keele sugulusele hiina keelega. Ta vaatleb sõnatüvesid ja -juuri, sõnamoodustust, võimalikke ühiseid tüvesid, sarnaseid lausungeid ning omastava käände ja omadussõnalise täiendi asendit, mis võiksid osutada erinevate kaugete keelte sugulusele. Ta teeb järelduse, et hiina keel on soome-ugri ja altai keeltega suguluses. Hermanni saksakeelne artikkel, mis ilmus aastal 1895, on tõlgitud eesti keelde.

Märksõnad: 19. sajandi keeleteadus, keelte sugulus, hiina keel, soome keel, eesti keel, soome-ugri keeled, altai keeled

DOI: https://doi.org/10.12697/jeful.2019.10.2.04

Kõige viimasel ajal on palju selle üle räägitud, kas Ida-Aasia suur kultuurkeel, hiina keel, on sugulussuhtes ugri keeltega või mitte. Nii mõneltki poolt on sellist sugulust eitatud, seevastu teised on selle kui kindla tõsiasja esile toonud. Viimaste hulka kuuluvad nende keelte parimad tundjad nagu W. Schott, Max Müller, H. ja G. von Gabelentz. Schott oletab sellist sugulust juba oma Berliinis ilmunud hiina keele grammatikas aastast $1857^{2}$ ega kahtle ka üksikuid sõnu samadena

1 Tõlgitud väljaandest Hermann (1895). Artiklis esinevate hiina keele sõnade hiina kirjamärgid ning nende vasted pinyinis on lisanud Jingyi Gao (hiina 高晶一, pinyinis Gāo Jīngyī). Tõlke on keeleliselt toimetanud Asta Niinemets. Tänan neid mõlemaid! Hermann on eesti ja soome keele eristamisel ebajärjekindel. Pealkirjas ja mitmel pool tekstis peab ta neid üheks keeleks Finnisch-Estnisch, nii nagu see oli 19. sajandi keeleteaduses üldiselt tavaks. Soome keelt ja eesti keelt peeti ühe keele murreteks. Teisal aga kirjutab Hermann eraldi soome keelest ja eesti keelest.

2 Võimalik, et Hermann eksib Schotti Berliinis ilmunud hiina keele grammatika (1857) osas. Toimetaja Pire Teras osutas, et viide sõnale kong on Schotti raamatus „Katse 
esitamast, nagu hiinakeelne kong ' 'tühemik, õõnsus; kong' on samatähenduslik soome [sõnaga] konkelo, mis on eesti keeles isegi täiesti sama kong. Max Müller „ei kõhkle“, et seda sugulust võib „,vaadelda kui täiesti väljaspool igasugust kahtlust seisvat ning kuulutada, et ka teised samasuguse morfoloogilise iseloomuga keeled on uurali-altai keeltega suguluses. Nii kuulutab ta draviidi keeled ja malai keeled tüüpilisteks turaani keelteks ning isegi Kaukasuse keelemurded, mida kaasaegne teadus omakeski nende kirevas mitmekesisuses ning üpris algupärasel kujul senini ühtegi genealoogilisse seosesse tuua ei ole suutnud, on Max Mülleri jaoks suure turaani keelepuu haru" - nii kirjutab Friedrich Müller oma „Keeleteaduse põhijoontes“. G. von der Gabelentz oli juba aastal 1878 sellist sugulust rõhutanud ning seejärel Berliinis oma akadeemikuks valimise pidukõnes esile tõstnud. Friedrich Müller, kes süüdistab Max Müllerit, et tollel on teaduslikult liiga vähe põhjendatud vaated sugulussuhete kohta, ei saa siiski mööda, et ugri-soome, türgitatari, päris-mongoli ja mandžu-tunguusi keeled, korea keel ja ühesilbilised keeled nagu tiibeti, birma, siiami [tai], annamiidi [vietnami] ja hiina, sinna juurde ka Himaalaja, lohita [lolo], miaotse [hmongi], khasi ja talaingi ehk peguaani [moni] keeled tuleb kõik üles lugeda sugulaskeeltena ühise nimega „mongoli keeled“, samal ajal kui ta malai keeli ühelt poolt ja draviidi keeli teiselt poolt enam ühisesse tüvesse ei paiguta, vaid pigem peab neid mongoli keelte naabruses olevateks või ka neist mõjutatud, kuid iseseisvateks keeletüvedeks [keelkondadeks].

Olgu aga siin öeldud, et nende keelte vaheliste sugulussuhete teaduslikuks põhjendamiseks on toodud väga vähe faktilist materjali. Ülesanne on selleks liiga suur, et see laseks end lahendada põgusa materjali kogumise põhjal lühikeses uurimistöös. Siiski ei või teaduse meestelt, kes on selle kohta siin oma arvamuse kujundanud, võtta õigust oma arvamust väljendada, seda enam, et on vaevalt oodata, et mõni riik või mõni instituut annaks selleks vahendeid, millega õpetlased selle hiigelülesande lahendamiseks saaksid töötada. Indo-germaani keelte uurimisel on olnud ja on ka praegu väljapaistvaid esindajaid, kes selle

kirjeldada hiina kirjandust“, kus ta ühes joonealuses märkuses selgitab, et $K$ 'ong-tssè (Konfutsiuse) nime esimene pool 'õõnsus' on samane soome tüvega konke-lo 'puuõõs' (Schott 1854: 6). Lisan, et Schott on kasutanud hiina k'ung ja soome konke-lo tüvede vastavuse näidet juba varem (Schott 1849: 60).

3

孔, kǒng. 
rahvastepere keelte sugulusseoseid on põhjalikult selgitanud, ugro-altai keelte uurimisel ei ole sarnaseid uurijaid ette näidata, ja kes ka on seal olnud, ei ole heitnud küsimusele täit valgust. Nimetatud teadusemehed ei ole ka seda teinud, on aga selle kohta arvamuse kujundanud, mida ma omalt poolt meeleldi kaitsta sooviksin selle läbi, et ma vähemalt mõne välise tõendi selle vaate juurde esitan.

Hiina keele üldtuntud omadus seisneb selle sõnade ühesilbilisuses. Ometi on seda keele selgeks õppimisel vaevalt rohkem märgata kui teiste keelte puhul, kuna väga paljud hiina keele sõnad on liitsõnad ning sellistena esinevad mitmesilbilistena. Iga hiina keele sõna puhul võib aga väikese vaevaga märgata, et see koosneb kahest või rohkemast ühesilbilisest sõnast. Just seda hiina keele ühesilbilisust tuuakse nüüd tõendiks selle keele ja ugri-soome keelte suguluse vastu, kus viimastes on väga palju mitmesilbilisi sõnu, ja isegi nende keelte iseloomu võib nimetada pigem mitmesilbiliseks. Sellega ei ole aga tegelikult nii, vaid hiina keele sõnade ühesilbilisus osutub lähemal vaatlusel suguluse tõendiks. Kui võtame soome keele ja vaatame selle sõnatüvesid, siis leiame, et need on eranditult kahesilbilised. Aga teine silp tekib ainult niinimetatud sidevokaali abil, mis vahendab sidet sõnatüve ja muutelõpu vahel. Ilma igasuguse kahtluseta ei kuulu see sidevokaal algselt tüvevokaali juurde, vaid on ise teatud liiki sufiks, sõna moodustav element, mis on esmalt aja jooksul tekkinud, või teatud tüüpi artikkel, millist leiame näiteks rootsi keelest, kus see paikneb nimisõna lõpus. Seda, et see on õige, tõendab juba asjaolu, et sidevokaal on ühel ja samal sõnatüvel erinev vastavalt sellele, kas ta moodustab nimi- või ajasõna. Nii näiteks on [saksa] „Lesen“ [vaste] tüve nimisõnatüvi „lugu“ ja ajasõnatüvi „luge“, [saksa] „Sorgen, Drücken, Sterben“ [vaste] tüve nimisõnatüvi „suru“ ja ajasõnatüvi „sure“ nii soome kui ka eesti keeles. Nimisõnatüvel leiame siin sidevokaali $-u$ ja ajasõnatüvel sidevokaali $-e$. Järelikult on puhtad juured nende sõnade puhul „lug" ja „sur“, seega hoopis ühesilbilised täiesti nagu hiina ja teiste ühesilbiliste keelte sõnade puhul. Ometi on soome ja selle sugulaskeeltes arvukalt mitmesilbilisi sõnu, siiski saab nende tekkimist selgitada eranditult sõnamoodustuslõppude abil, ning ainult sõna peajuurt moodustav esimene silp ei ole sufiks, vaid iseloomu, mõtet, peatähendust andev element. Eesti keeles võib isegi kõige pikemate, näiliselt jaotamatute mitmesilbiliste sõnade puhul kerge vaevaga ära tunda, et need on sõnamoodustussufiksite abil ühesilbilistest juurtest laiendatud moodustised, nii näiteks on õnn-i-s-tu-s, õnn-i-s-ta-mi-ne, 
õnn-i-s-ta-ma pärit juurest õnn, sõnatüvi õnn-e, kusjuures $-i$ ja $-e$ tulevad nähtavale sidevokaalidena, samal ajal kui kõik ülejäänu koosneb sõnamoodustussufiksitest. Täpselt samuti on teiste ugri keeltega, niisamuti ka madjari [ungari], türgi ja mandžu keeles. Hiina keeles on algusest peale olnud ainult ühesilbilised juured. See keel sai juba siis omale kirja, kui ta alles paljastest juurtest koosnes, sellest ka jäik struktuur, mis ilmselt paistab, ei ole orgaaniliseks arenguks võimeline. Kuid ometi on arvukad hiina keele liitsõnad tõendiks mitmesilbilisuse tekkimisest hiina keeles, sest väga paljudel juhtudel ei ole liitsõnade teises ja kolmandas silbis kasutatud sõnade iseseisev tähendus enam tõestatav ning need on muutunud puhasteks sõnamoodustussufiksiteks - üsna samamoodi nagu ugri keeltes sellised sufiksid, mida sõnamoodustuselementidena kasutatakse, olid kahtlemata iseseisvad sõnad, kui ka ei ole võimalik nende algtähendust igal üksikul juhul kindlaks teha. Hiina keeles on sõnamoodustuses isegi prefiksid kasutusel, mis meenutab indo-germaani keelte struktuuri. - Sellisel viisil on hiina keel võimeline moodustama üksikuid käändeid, mille puhul teatud sõnakesi, mille tähendus ei ole enam teada, kasutatakse lõppudena, nii kasutatakse genitiivi puhul sõna järel $-t s c h i^{4} \mathrm{ja}-t i^{\prime}{ }^{5}$, daativi puhul $t u i^{6}, k e^{7} \mathrm{jt}$ sõna ees, akusatiivi puhul $p a^{8}$ ja tsiang ${ }^{9}$ sõna ees jne. Need sõnakesed vastavad täiesti teiste, sh ugri keelte käändelõppudele. Iseenesestmõistetavalt ei saa salata, et siin on suguluses sufikseerimise viis, mitte aga sufiksid ise. Hiina keelel oli nimelt keelena juba kohe algusest peale kirjalikult fikseeritud kuju, mille tõttu ei saanud enam toimuda edasine areng nii rikkalikus mitmekesisuses nagu see toimus nende keelte puhul, mis juba enne suulise kõne kirjalikku fikseerimist end läbi suurema sõnamoodustuselementide sulandumise vormirikkamaks kujundasid. Piiratud arv sõnajuuri ei anna võrdluseks kuigi rikkalikku materjali, kuid nõrgal liitmise viisil on lähim sugulus ja suurim sarnasus sellega, mida keeleteadlased nimetavad ugri keelte aglutinatsiooniks, samal ajal kui hiina keele ühesilbilisus ei osutu mingiks takistuseks hiina keele ja ugri

$$
\begin{aligned}
& \text { 之, } z h \bar{\imath} . \\
& \text { 的, di/de. } \\
& \text { 對, duì. } \\
& \text { 給, gěi. } \\
& \text { 把, bă. } \\
& \text { 將, jiāng. }
\end{aligned}
$$


keelte vahelise suguluse tunnistamiseks, kuna kõigi nende keelte sõnajuuri saab algselt tuvastada ühesilbilistena.

Sõna algushäälikute suhtes on hiina keelel samuti sarnasus ugri keeltega. Nagu nendelgi, on hiina keele algushäälik üldiselt lihtne. Harva kasutatakse sõna alguses kaksikhäälikuid, ning isegi väga konsonantselt [st helitult] kõlavaid sisihäälikuid [sibilante] $f, \operatorname{sch}[\check{s}]=u$ ja $t s c h[\check{c}]=u$ võtab keel kui lihtsaid konsonante. Igal juhul on selliseid algushäälikuid ka paljudes ugri keeltes, nii näiteks madjari keeles, kui ka need kolm soome ja eesti keeles puuduvad, on kõik ülejäänud aga olemas. Ning need ülejäänud on otsustava tähtsusega, kuna need moodustavad reegli.

Hiina keele sõna lõpphäälik on kas vokaal või $-n$, neist viimane häälik esineb sageli nasaleeritult -ng, nagu see peaks teada olema Hiina kohanimedest Peking, Nanking, Fukiang jne. Lõpphäälikud $p, t, k$ esinevad ainult murretes või eriliste hälikuseaduste tõttu või vastavalt onomatopoeetikas. Tähelepanuväärne on nüüd, et vokaalne lõpphäälik koos lõpphäälikuga - $n$ langeb kokku samade lõpphäälikutega soome keele sõnades, soome keeles puudub ainult nasaleeritud lõpphäälik - $n g$, samal ajal kui soome keeles lõpphäälikud $p, t, k$ samuti erandkorras esinevad täiesti nagu hiina keeles. See on igal juhul üks märkimisväärsemaid kokkulangevusi, mis ei saa hoopiski mitte juhus olla.

Grammatilise soo märkimist artikli või teatud lõpu abil leidub hiina keeles niisama vähe nagu kõigis ugro-altai keeltes. Loomulikku sugu väljendatakse eri sõnadega, nähtusega, mis samuti kordub kõigis selle rahvastepere keeltes ja mis on oluline suguluse tunnus.

Hiina keele ja ugri keelte vahelise suguluse vastu esitatav tõend on, et teadaolevad hiina sõnad, mis oleksid identsed samade sõnadega ugri keeltes, sama hästi kui puuduvad täielikult. Ometi kaotab see tõend jõu nii iseenesest kui ka hiina keele väga piiratud sõnavara tõttu, mis ei sisalda mitte rohkem kui poolteist tuhat erinevat sõnatüve. Peaaegu igal sõnal on neli, viis ning isegi kümme või kakskümmend tähendust. Seetõttu on hiinakeelne kirjavara kõigi mittehiinlaste jaoks väga keeruline ning lakkamatult esineb sagedast vääritimõistmist, mille puhul isegi sünnipärased ning õpetatud hiinlased sageli nõutuks jäävad.

Et aga isegi tunnustatud autoriteedid, nagu Schott, ei ole selle peale mõelnud, et otsida samamoodi või sarnaselt kõlavaid sõnu ning näha neid suguluses, on osutatud juba [selle artikli] alguses. Schott esitas [hiina sõna] kong ‘õõnsus, kong' kui suguluses oleva samatähendusliku soome keele [sõnaga] konkelo, eesti kong. Paljud õpetlased on viidanud, 
et omadussõna „hea, ilus“ kõlab hiina keeles $h a o^{10}$, türgi keeles eyi, madjari keeles jó, soome keeles hyvä, eesti keeles hää, hea, hüva, niisiis on see igal pool väga sarnane. Hiina keeles kutsutakse „teed“' 'Weg' sõnaga $t a o^{11}$, soome keeles tie, eesti keeles tee. Hiina keeles on „naine, neiu“"niu' ${ }^{12}$, mandžu keeles nei-nei, madjari keeles nö, né, soome keeles neito, neiti, nainen, eesti keeles neid, neiu, neidi, naene. Hiina keeles on „süda“" $\sin ^{13}$, soome keeles sydän, eesti keeles süda, murdeti süa-. Koreamaa nimi peaks olema samane hiina sõnaga $\mathrm{kao}^{14}$ 'kõrge', see sõna on soome keeles korkea, eesti keeles kõrge (kuna hiina keeles puudub $r$-häälik, siis võib väga hästi korea olla samane sõnaga kao). Hiina keeles kutsutakse ,puud, puitu“ $m u^{\prime}{ }^{15}$, mis võib väga hästi olla samane soome-eesti sõnaga $p u u$, kuna ka muidu algushäälik $p$ vastab sageli $m$-häälikule. Võib-olla ei ole see juhus, et ainsuse kolmanda isiku asesõna on hiina keeles $t^{\prime} a^{16}$ ning eesti keeles samuti $t a$.

Need on ainult mõned suguluses olevateks peetud sõnatüved. Täpsemal sõnavara võrdlusel leitaks neid palju rohkem.

Uuemal ajal tuuakse tugevaima tõendina kahe erineva keele suguluse kohta sarnaste väljendite ja vanasõnalaadsete ütluste sagedust. Just selles on hiina keelel tõesti palju sarnasust soome ja eesti keelega. Eestlane tähistab tallinlast „Tallinna mees“ (sks Revalenser), tartlast „Tartu mees“ (sks Dorpatenser), pärnakat „Pärnu mees“ (sks Pernauiter), mis on saksa keeles sõna-sõnalt „Revals Mann“, „Dorpats Mann“, „Pernaus Mann“; täpselt nii toimib ka hiinlane kui ta ütleb nt pekinglase (sks Pekinese) asemel „Pe-king jin“17 (жін), nankinglase (sks Nankinese) asemel „Nan-kin jin“18, kantonlase (sks Cantonese) asemel „Kuangtung jin“"19, seega „Pekingi mees“, „Nankingi mees“ ja „Kantoni mees“. Hiinlast kutsutakse hiina keeles „Tschung-kuok-jin“ ${ }^{20}$, eesti keeles seega „Hiina-riigi mees“ või „kesk-riigi mees“. Hiina keeles nimetatakse

\footnotetext{
10 好, hăo.

11 道, dào.

12 妞, niū.

13 心, xīn.

14 高, $g \bar{a} o$.

15 木, mù.

16 他, $t \bar{a}$.

17 北京人, běi-jīng-rén.

18 南京人, nán-jīng-rén.

19 廣東人, guāng-dōng-rén.

20 中國人, zhōng-guó-rén.
} 
silmapaistvalt suurt hulka viisil „hea arv“ (sks eine Gute Anzahl), nt hao suan jin ${ }^{21}$ „hea hulk inimesi“" (sks eine ansehnliche Anzahl Menschen või sõna-sõnalt eine gute Anzahl Menschen), hao-ki pe'-ko jinn (sks einige hunderte Menschen) - samamoodi ka eesti keeles hää arv inimesi (sks eine bedeutende (,,gute“) Anzahl Menschen), mõni hää sada inimesi (sks manches ,gute " Hundert Menscen, st mehrere Hundert Menschen). - Hiina keeles öeldakse sien-scheng-ti'sie-liao schu-king ${ }^{23}$ (sks ein von einem Gelehrten geschriebenes Buch) üpris samamoodi nagu eesti keeleski „õpetatud mehe kirjutatud raamat“. - Hiina keeles kutsutakse taevalaotust (sks Firmament) või kogu maailma (sks Welt) tien-hia ${ }^{24}$ (sks des Himmels Unters) täpselt nagu eesti keeleski taevaalune. Hiina keeles öeldakse tschung-lui ${ }^{25}$ (sks der Käfer Geschlecht) nagu eesti keeleski ,putukate tõug“. Nii võib veel suurel hulgal sarnaseid ütlusi leida, mille teke ei saa kindlasti olla lihtne juhus. Ma arvan, et väljendid ei saa olla üldse juhuslikud, vaid et vastastikku samased väljendid peavad juba algselt suguluses olema.

Ma pean mainima veel ühte eripära, mis kindlasti pole kõige nõrgem argument. See on omastava käände nagu ka omadussõna asend. Pärast hiina keele sõnajuurte jäikust ja paindumatust on peaaegu iseenesestmõistetav, et omadussõnaline täiend (sks Adjectiv als Attribut) jääb käändumatuks - täiesti samamoodi nagu see on mandžu, türgi ja madjari keeles ning nagu see tõendatavalt pidi olema ka soome-eesti keeles, kus ainult nimisõna saab käändelõpu. Juba see eripära on sugulusele osutav tunnus. Aga veel rohkem tunnistab sugulust omastava käände ning omadussõnalise täiendi asend alati subjekti või objektina rakendatud nimisõna ees. Seesama kehtib ka ase- ja arvsõnade kohta seal, kus nad esinevad täiendina. Hiina keeles on täiendid nimisõna järel

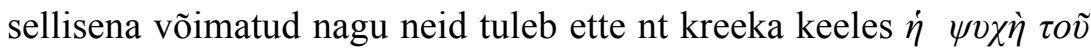
$\dot{\alpha} v \theta \rho \omega ́ \pi o v, \dot{\alpha} \ddot{\alpha} v \theta \rho \omega \pi o \varsigma \dot{\alpha} \gamma \alpha \theta \dot{\varsigma}$ või ladina keeles animus hominis, vir bonus või sama vene keeles душа человъька, человъькь добрый [sõnasõnalt 'hing inimese, inimene hea'], hiina keeles saab neid väljendeid

21 (ei ole kehtiv) 好算人, hăo suàn rén.

22 好幾百人, hăo jǔ băi rén.

23 (ei ole kehtiv) 先生的寫了書經, xiān-shēng-de xiě-liăo shü-jīng.

24 天下, tiān-xià.

25 蟲類, chóng-lèi. 
moodustada ainult eelneva täiendiga jin-ti' ling-houn ${ }^{26}$, hao jin ${ }^{27}$, ,inimese hing, hea inimene“ „des Menschen Seele, guter Mensch“, täpselt samuti nagu ka mandžu niyalma-i enduri, sain haha, türgi keeles adamyn ruh, eyi insan, madjari keeles az embernek lelke, jó ember, soome keeles ihmisen henki, hyvä mies, eesti keeles inimese hing, hää mees. Nendest näidetest on väga hästi näha ugro-altai keelte täiendi erinevus indo-euroopa (indo-germaani) keelte omast. On tõsi, et mitte kõik indo-germaani keeled ei aseta täiendit samal viisil nimisõna taha, nii nt võib saksa keeles öelda nii „die Seele des Menschen“ 'hing inimese' kui ka „des Menschen Seele“ 'inimese hing' ning koguni ainult „der gute Mensch“ "hea inimene', kuid mitte kunagi „der Mensch gute“ "inimene hea', kuid see ei ole tõend hiina ja ugro-altai keelte suguluse vastu, vaid pelgalt analoogia.

Need on lühidalt hiina keele kokkulangevused ugro-altai keeltega, eriti soome-eesti keelega. Seda ei ole just palju, sest sama tüve keelte suguluse peamiseks tõendiks jääb ikkagi identsete sõnatüvede sagedus, mis siin enamasti puuduvad. Aga nagu juba öeldud, piiratud arvu hiina keele sõnajuurte puhul ei ole see imekspandav. Aga siiski on ühelt poolt hiina keele ja teiselt poolt vaieldamatult esimesega suguluses olevate samamoodi ühesilbiliste vietnami ja korea keelte vahel identsete sõnajuurte arv vähene. Nii keeleseaduspärade kokkulangevus kui ka sõnamoodustuse sama viis on igal juhul samuti keelte suguluse tõendiks, ning kaheldamatult leian ma selle tunnuse nii hiina keelest kui ka ugro-altai keeltest. Seda, kuidas keeleteadlaste poolt aglutinatsiooniks nimetatu teoks saab, näitab hiina keele liitsõnade ja käändevormide moodustamine selgemini kui ükski keeleseaduspära. Omalt poolt lisan, et ma ei suuda aglutinatsiooni ja fleksiooni vahet leida, resp. vähem väljaarenenud keeleseaduspära toimib nagu teinegi: [sõnadest] näge-ma ja vide-re on olevik: näe-n, näe-d, näe-b, näe-me, näe-te, näe-wad; vide-o, vide-s, vide-t, vide-mus, vide-tis, vide-nt; minevik: näg-i-n, näg-i-d, näg-i, näg-i-me, näg-i-te, näg-i-vad; vide-ba-m, vide-ba-s, vide$b a-t$, vide-ba-mus, vide-ba-tis, vide-ba-nt. Nii eesti kui ka ladina keeles liituvad [tunnused ja] lõpud tüvele täpselt samal viisil. Ka siin kattuvad aglutinatsioon ja fleksioon. Teatud indo-germaani keeltes olemas olevate keeleseaduspärade puudumine nagu ka suurem algne sarnasus

26 人的靈魂, rén-de líng-hún.

27 好人, hăo rén. 
sõnamoodustuses kallutavad aga soome-eesti keelt rohkem hiina keele poole.

Toetudes kõigele sellele, võin ma öelda: hiina keel on ugro-altai keeltega suguluses nagu ka soome-eesti keelega. Hiina keel on kõige tugevam ja jämedam haru puul, mille rohkem või vähem peenemad harud on kõik ugro-altai keeled - sealhulgas nii jaapani ja korea, mandžu mongoli, türgi, aga ka madjari, mari, mordva, lapi, soome ja eesti keel.

\title{
Kirjandus
}

Hermann, Karl August (1895) „Ueber die Verwandtschaft des Chinesischen mit den ugrischen Sprachen und insbesondere mit dem Finnisch-Estnischen“. Sitzungsberichte der Gelehrten Estnischen Gesellschaft 1894, 167-180. Dorpat: C. Mattiesen.

Müller, Friedrich (1876) Einleitung in die Sprachwissenschaft. (Grundriß der Sprachwissenschaft, Bd. 1, Abt. 1.) Wien: Alfred Hölder.

Schott, Wilhelm (1849) Über das Altai'sche oder Finnisch-Tatarische Sprachengeschlecht. Berlin: Reimer.

Schott, Wilhelm (1854) Entwurf einer beschreibung der chinesischen litteratur. Eine in der königl. preuss. akademie der wissenschaften am 7. februar 1850 gelesene abhandlung. Berlin: Dümmler.

Schott, Wilhelm (1857) Chinesische Sprachlehre. Zum Gebrauche bei Vorlesungen und zum Selbstunterrichtung. Berlin: Dümmler.

\begin{abstract}
Karl August Hermann: About the relationship of Chinese with the Ugrian languages and especially with the Finnish-Estonian (1895). Karl August Hermann (1851-1909), an eminent Estonian linguist, encyclopedist and composer in the nineteenth century, identifies features that might indicate the affinity of Ugrian, i.e. Finno-Ugric and Altaic languages, including Estonian and Finnish, with Chinese. He looks at word stems and roots, word formation, possible common word stems, similar utterances, and the position of the genitive and the adjective in relation to the noun that might indicate the affinity of different distant languages. He concludes that Chinese is related to FinnoUgric and Altaic languages. Hermann's forgotten article, published in German in 1895 , has been translated into Estonian by Urmas Sutrop.
\end{abstract}

Keywords: 19 th century linguistics, linguistic affinity, Chinese, Finnish, Estonian, Finno-Ugric languages, Altaic languages 